\title{
Research Status and Development Trend of Dimethyl Ether Fuel Supply System
}

\author{
Jing Sun ${ }^{\mathrm{a}}$, Guangde Zhang, Caixia You, Qiang Yao and Zhonghai Hou
}

School of Automobile and Traffic Engineering, Wuhan University of Science and Technology, Wuhan 430081, China

a67565050@qq.com

Keywords: Dimethyl Ether; Engine; Fuel Supply System; Common-rail System.

Abstract. A survey of study on dimethyl ether engine fuel supply system at home and abroad was described, including pump-pipe-nozzle system and common-rail fuel supply system. The main trouble of practical application of dimethyl ether engine is wear and leakage problems in the fuel delivery system caused by low viscosity of dimethyl ether. For controllable premixed combustion of dimethyl ether engine, a fuel injection system is developed which is consisted of a diaphragm pump and a wear self-compensation nozzle or an independent lubrication nozzle. The system is expected to solve the above problems essentially and becomes a development direction for the future.

\section{Introduction}

Currently, oil resource keeps decreasing and oil price keeps rising. Meanwhile, car ownership grows rapidly due to the fast development of China's economy, which calls for significant increase of energy and grows of environmental hazards. Facing the dual challenges of energy shortage and environmental pollution, developing new alternative fuels has attracted growing concerns of researchers in order to realize low emissions and high efficiency of internal combustion engine.

As a traditional fuel, the use of diesel is limited because of the high $\mathrm{NO}_{\mathrm{X}}$ and particulate emissions of diesel engines. Over the years researchers around the world have proposed many solutions. However, in order to solve energy shortage and environmental pollution problems fundamentally, development of new alternative fuels are necessary. Studies on dimethyl ether by the United States and some European countries found that engines filled with dimethyl ether have good power performance, fuel economy and ultra low emission. At the same time it can significantly reduce NOx emissions and exhaust smoke almost reaches zero. All of this make dimethyl ether receive wide attention. Since there are many differences between the physical and chemical properties of dimethyl ether and diesel, to retrofit existing diesel fuel injection system to fit DME fuel is still the key to current development of dimethyl ether engine.

Physicochemical properties of DME and diesel are given in table 1. Dimethyl ether, referred to DME and its molecular structure is $\mathrm{CH} 3-\mathrm{O}-\mathrm{CH} 3$. It is a non-toxic and environment-friendly fuel, which can be produced by the conversion of various feedstock such as nature gas, coal, oil residues and bio-mass. As an alternative fuel for diesel engines, because of its high oxygen content (around 35\% by mass) and the absence of $\mathrm{C}-\mathrm{C}$ bonds in the molecular structure, virtually smokeless combustion can be achieved. In addition, spontaneous combustion of DME is good due to its high cetane number (>55) and that is why it can be used in compression-ignition engine.

Table 1 Properties of DME and diesel fuel

\begin{tabular}{|c|c|c|c|}
\hline Properties & Unit & $\begin{array}{c}\mathrm{DM} \\
\mathrm{E}\end{array}$ & Diesel fuel \\
\hline $\begin{array}{c}\text { Oxygen } \\
\text { content }\end{array}$ & $\begin{array}{c}\% \\
\text { mass }\end{array}$ & $\begin{array}{c}34 . \\
8\end{array}$ & 0 \\
\hline $\begin{array}{c}\text { Critical } \\
\text { pressure }\end{array}$ & $\mathrm{MPa}$ & 5.3 & 3 \\
\hline $\begin{array}{c}\text { Liquid } \\
\text { viscosity }\end{array}$ & $\mathrm{kg} / \mathrm{m}^{-}$ & 0.1 & $2 \sim 4$ \\
\hline
\end{tabular}




\begin{tabular}{|c|c|c|c|}
\hline $\begin{array}{c}\text { Cetane } \\
\text { number }\end{array}$ & & $>55$ & $38 \sim 53$ \\
\hline $\begin{array}{c}\text { Auto-ignition } \\
\text { temperature }\end{array}$ & $\mathrm{K}$ & 508 & 523 \\
\hline $\begin{array}{c}\text { Boiling point } \\
\text { at 1 atm }\end{array}$ & $\mathrm{K}$ & $\begin{array}{c}248 \\
.1\end{array}$ & $450 \sim 643$ \\
\hline $\begin{array}{c}\text { Enthalpy of } \\
\text { vapourization }\end{array}$ & $\mathrm{kJ} / \mathrm{kg}$ & $\begin{array}{c}467 \\
.13\end{array}$ & 300 \\
\hline Heating value & $\begin{array}{c}\mathrm{MJ} / \mathrm{k} \\
\mathrm{g}\end{array}$ & $\begin{array}{c}27 . \\
6\end{array}$ & 42.5 \\
\hline
\end{tabular}

\section{Research Status of DME Engine Fuel Supply System}

Dimethyl ether engine fuel injection system involves traditional pump-pipe-nozzle system, new variable displacement pump system and common-rail system. Typically, for light-duty vehicles, which not require high reliability, dimethyl ether fuel injection system is modified traditional pump-pipe-system [1].

Research on Pump-line-nozzle Dimethyl Ether Fuel System. Sorenson et al. of Denmark University [2] modified the pump-pipe-nozzle system and tested it in a small non-turbocharged single cylinder engine (displacement volume 0.237L) filled with DME. Some changes were made to ensure DME work normally. Experiments showed that for small single-cylinder direct-injection engine, using DME after reforming the traditional pump-pipe-nozzle system is feasible and reforming costs are very low. Pump-pipe-nozzle system can make full use of traditional diesel fuel injection system, so it is also one of its major advantages.

Christensen and Sorenson et al. of Denmark University [3] also made comparison test of DME and diesel with ordinary pump-pipe-nozzle system. Results indicate that there is a clear secondary injection phenomena since DME is easy to be compressed and traditional fuel pump has fuel leak, plunger couples wear problems. So, conventional pump-pipe-nozzle fuel injection system is not suitable for DME engine. Similarly, rotary injection pumps and unit pumps also have such kinds of issues. On the other hand, Tsuchiya and Sato [4] pointed out that an in-line fuel-injection pump (jerk type) with conventional spring-loaded needle injector was more suitable than a common-rail system for heavy-duty DME engines due to the maximum injection pressure characteristics.

In all, although the traditional pump-pipe-fuel system has some advantages for dimethyl ether engine, since appropriate improvements are needed and the process of transformation is complex, it is not the main direction of future development.

\section{Study on Dimethyl Ether Common-rail Fuel System}

Features and components of common rail fuel system. Injection pressure is independent from the engine speed and load for the common-rail fuel supply system, so fuel injection timing, fuel injection delay and injection rate can be easily optimized to make the engine applied with common-rail fuel supply system work efficiently. Although DME is easily to be compressed, common-rail system is not very sensitive to it. Meantime plunger couples of the traditional high pressure fuel pump can be leaved out for common-rail fuel supply system and this solved problem of pair clearance leakage in plunger couples caused by wear. Therefore, targeted design of common-rail fuel injection system may be more suitable for DME engine.

Common-rail system consists of two major components: fuel storage, supply parts and fuel injection parts. For fuel storage, supply parts, due to the similar physical properties of dimethyl ether and LPG, existing LPG storage and transportation way can be used for DME.

DME engines have good performances when DME common-rail system bear pressure no more than $30 \mathrm{Mpa}$, while for diesel engines, the pressure can be over $160 \mathrm{MPa}$. It is the significant difference 
between design of common-rail fuel injection systems for DME and diesel. High pressure fuel pump is a key part in the common-rail system. Since dimethyl ether has low viscosity and is easy to be compressed, traditional high pressure pump is not suitable for DME common-rail system. AVL Company has developed a variable displacement pump.

Research of common-rail fuel system at home and abroad. Many universities at home have launched studies on dimethyl ether common-rail fuel system. Zhang Xiao, Wang Yang, et al. from Tianjin University [5] designed a electronically controlled common-rail injector. There's a t-block instead of a hydraulic piston in the designed injector and oil port is also left out, meantime solenoid directly drives needle valve. All this solved the wear and leakage problems between plunger couples. They also conducted simulation studies on fuel injection laws of this injector. Zhou Xiaoxin from Shanghai Jiaotong University [6] established a common-rail fuel injection system model of dimethyl ether engine and offered a optimization of fuel injection system through simulation of the common-rail tube structure, fuel injection starting point and common rail pressure. Due to the following properties of dimethyl ether: low boiling point; easy to vaporize; oil supply pressure not exceed $25 \mathrm{Mpa}$ and injection pressure not over $30 \mathrm{MPa}$, my research team make the assumption of DME low-pressure common-rail fuel system. We also conducted simulation studies on injection characteristics of the fuel system and developed appropriate electronic control injection system [7].

After analyze various existing DME fuel supply systems comprehensively (including the common rail fuel system and pump-pipe-nozzle system), James and other researchers [8] who come from the AVL Company devised a new fuel injection system, shown in Figure 2. In this system, with the original oil return channels of the injector blocked, and then add an oil return way at the entrance to the injector. The return way was installed in the throttle and the back pressure valve. When having signal from ECU, the solenoid valve between the common rail unit and the injector opened, and high-pressure DME in common rail chamber flow to the injector, at the same time, producing the throttle effect generate which due to a sharp rise in pressure, and then the injector work; when the solenoid valve closed, the pressure in high pressure oil line fell rapidly, and the throttle effect loss, so DME back to the low-pressure oil through the orifice, fuel injector shut down to stop the fuel injection. For the orifice which can avoid the second injection effectively, and the injection pressure of the injector can be changed by adjusting the back pressure regulating valve. The experiments show that this system perfectly suits to the DME spray, but the hydraulic piston pump wear more seriously.

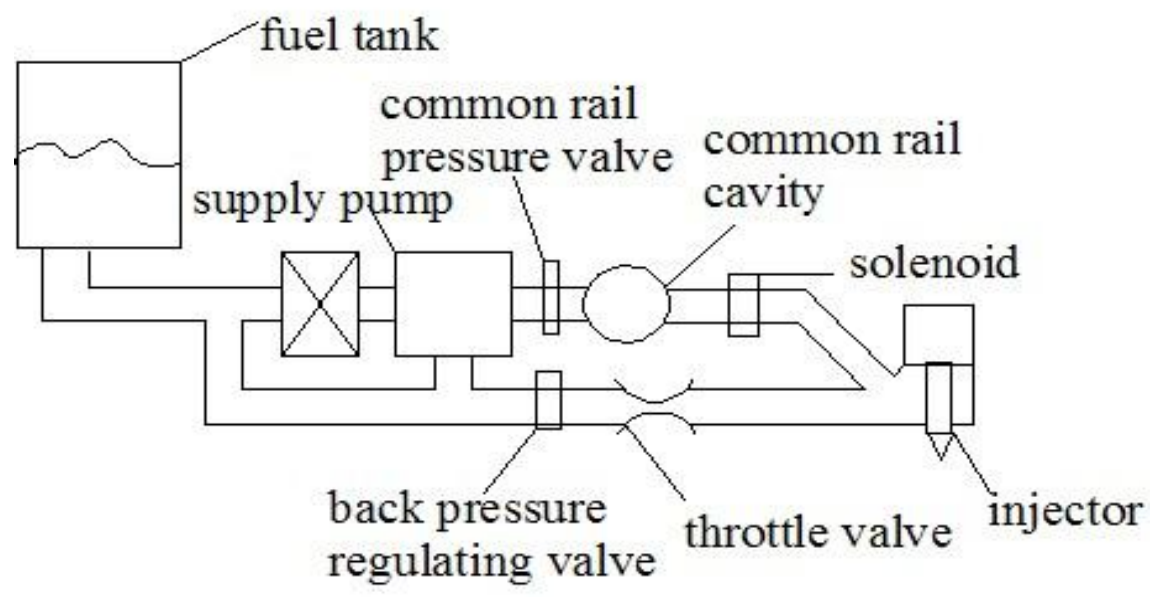

Fig. 1 dimethyl ether fuel injection system with throttle valve

\section{Study on Dimethyl Ether Lubrication and Wear}

DME lubricating wear research abroad. Because of low viscosity of DME, the key point is to solve wear and lubrication of the DME engine fuel supply system. Some scholars have pointed that mixing the other fuel with DME, such as diesel etc.; Or to solve the problem by adding castor oil and other additives in the DME. But this will reduce the advantage of fueled with DME. In addition, Additives, or how to determine mixed fuel of DME proportional that need further study. Currently, the 
technical measures in control leakage and wear including: Using DME-Diesel Dual Fuel, Reducing the injection pressure and Adopting the back pressure control leakage.

In these respects, the technology is relatively mature is mainly AVL Company. AVL Company cooperated with FORD and they carried out the research on the DXATA four-cylinder engine. In the experiment, we add propane isolation layer in the tank, then increasing saturated vapor pressure of DME pressure 10 bar. The high pressure pump is refitted by the hydraulic piston pump of swash plate. Between the common rail and injector, a two way solenoid valve is used to control the injector injection timing. The injector works similar to the traditional mechanical injector, this design is still not a fundamental solution to the wear and leakage problems.

The study on DME lubrication and wear in china. There are many universities have studied in the wear of DME in china. Huang Zhuoyong, Hu Tiegang and others [9] improved the research of the wear, and the result shows that put different kinds and proportion of lubricant in the fuel can bring the fuel system enough lubrication. Wang Ying and Zhou Longbao [10] had the research in the importance of lubricant to the DME engine, then the research shows that properly lubricant ensure the high performance of DME engine.

The strategy to prevent wear and leakage of the fuel injection system of DME engine. The research in fuel injection of DME engine of some relative researchers worldwide shows that [11] HCCI is better to DME engine for its good adaptability to fuel. To the problem [12] of HCCI can easily lead to flameout on low load and deflagration on high load, the team put forward CPC of DME to and developed a burning system consists of the main combustion chamber and pre-mixing chamber (vice-combustion chamber). On one hand, previous studies show that the common-rail system is more suitable for DME engine; On the other hand, for the volatility of DME, and the fuel is injected into the pre-mixing chamber at early stages of the compression stroke, so injection pressure is controlled at about $10 \mathrm{MPa}$, then formed a low-pressure common rail system. Specific anti-wear and leakage strategy consists of two parts: Replace the traditional injection pump with diaphragm pumps described above; developed wear self-compensation injector and independent lubrication injector.

Hydraulic diaphragm pumps are generally used for petrochemical, mining and other industries, but if used directly in the DME engine, there will be many shortcomings of bulky, relatively low output pressure and large pressure fluctuation. Therefore, in order to meet the requirements of the automotive supply pump, the project team developed a line diaphragm fuel pump. The pump mainly consists of three parts, the power transmission, hydraulic oil supply control system, the pump head institutions. The working principle is the camshaft rotation to drive the plunger for reciprocating movement; With the reciprocating motion of the plunger, hydraulic oil squeeze the diaphragm, and rely on the flexible diaphragm back and forth agitation to achieve the purpose of the suction and discharge of liquid media.

The biggest feature of the diaphragm fuel pump is that DME and the plunger are completely separated by the diaphragm, then the wear and leakage of plunger can be solved radically by replacing traditional plunger pump with the pump, and it also takes the advantages like stable operation, high-frequency of tradition injection pump.

The follow figure 3 explains the principle of wear self-compensation injector and independent lubrication injector. 


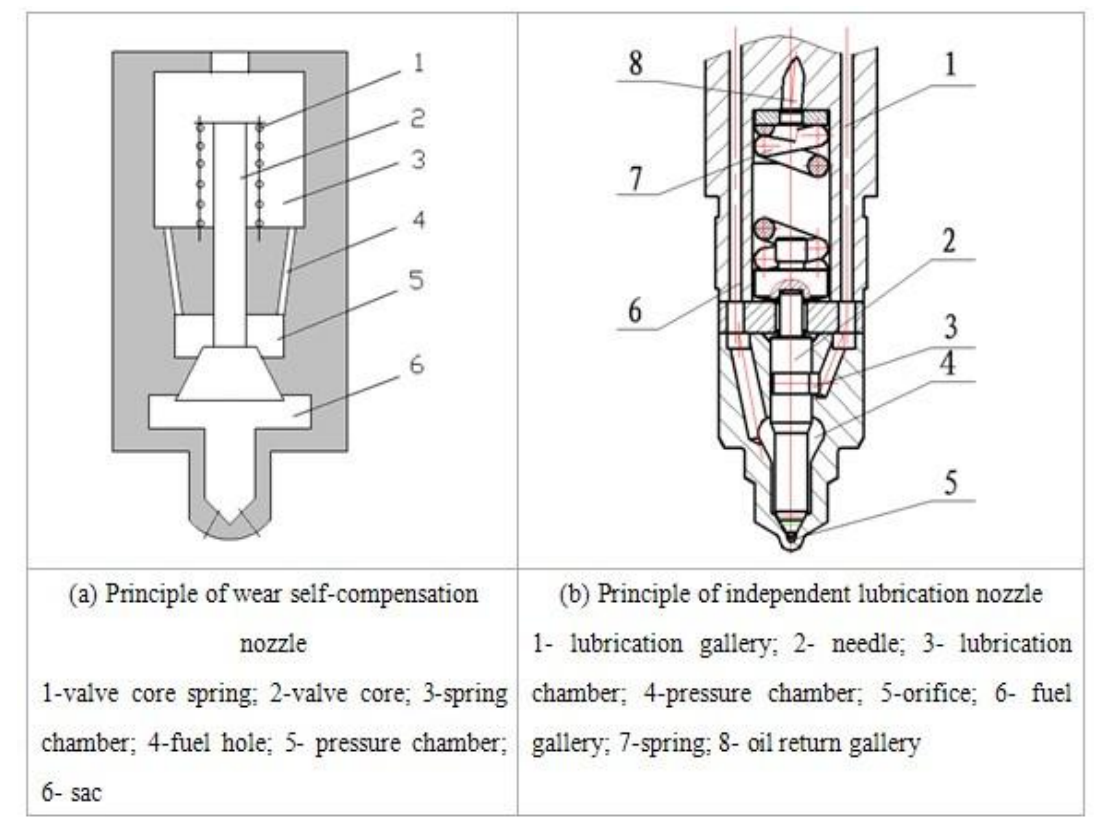

Fig. 2 principles of the new types of nozzles

Wear self-compensation injector cancel the oil return pipe and matching parts of traditional diesel fuel injector, the wear of the contact part of valve stem won't produce fuel leakage problem, and the wear of Spool cone can be compensated by the spool spring preload to ensure sealing cone reliable and sealed. From the principle of the structure we know that low viscosity DME is entirely feasible to wear self-compensation injector.

There is an independent lubrication injector in traditional diesel fuel injector. During the working course of the injector, the needle valve assembly lubricates by medium from external. To ensure suitable lubrication effect, we should avoid DME fuel penetrate from pressure chamber into lubrication chamber, therefore, the lubrication chamber pressure always slightly higher than state of injection pressure of DME.

The simulation experiment of Wear self-compensation injector shows that, the injection characteristics have reasonable trend, but as it relates to new injection principle, the law of its injection, the characteristics of spray and reliability should have further study. The simulation experiments of Independent lubrication injector show that the injector can not only ensure the lubricating effect of the needle valve but also suitable to choose the right lubricant. The movement of the needle valve and the feature of injection of the injector are reasonable. The leakage of lubricant is too small to the spray course and the movement of the needle valve.

\section{Summarize}

The worldwide research results show that DME as an alternative fuel of diesel is potential. To develop DME fuel system, the key point, we should solve the leakage of fuel, the wear and lubrication problems of precision parts. Second, we need develop the fuel supply device, according to the characters of DME that high compressibility and large pressure changes with temperature. Though the comparison of different supply systems, we know that the common rail fuel system is more suitable for DME engine. The electric-controlled common rail system of DME fuel supply will be a development direction in the future. For the wear and leak problems of DME engine injection system, much progress has also been made abroad. With further research, the DME engine will come true.

\section{Acknowledgements}

Project: National Nature Science Fundation Project (lot number: 50975212) 


\section{References}

[1] Constantine Arcoumanis, Choongsik Bae,el al. The potential of di-methyl ether as an alternative fuel for compression-ignition engines: A review.

[2] Spencer C Sorenson, Mikkelsen S: International Congress \& Exposition(Detroit, MI, USA, February 1995). SAE Paper 950064.

[3] M Christense, B Johnansson: International Fall Fuel and Lubricants Meeting and Exposition(San Francisco, California, October 19-22, 1998). SAE Paper 982454.

[4] Tsuchiya, Sato: Glass Applications (Detroit, MI, USA, April 2006). SAE Paper 2006-01-0052.

[5] Xiao Zhang, Yang Wang. A new type of electric control injection for common rail[J]. Journal of Tianjin University, Vol. 43 (2010) No.8, p.680-684.

[6] Xiaoxin Zhou, Junhua Fang: Diesel Engine, Vol. 31 (2009) No.3, p.5-8.

[7] Guangde Zhang: Vehicle Engine, Vol. 145 (2003) No.3, p.32-34.

[8] Ho Tengr James, Jeffrey: CI Engine Performance for Use with Alternate Fuel (Detroit, MI, USA, March 2002).SAE Paper 2002-01-0862.

[9] Yongzhuo Huang, Diegang Hu: Journal of Xi'An Jiaotong University, Vol. 39 (2005) No.3, p.233-237.

[10] Ying Wang, Li He, Longbao Zhou: Chinese Internal Combustion Engine Engineering, Vol. 30 (2009) No.3, p.24-26.

[11] Dongwon Jung, Oseock Kwon, Ock Taeck Lim:Journal of Mechanical Science and Technology, Vol. 25 (2011) No.6, p.1383-1390.

[12] Koichi Hatamura. A Study on HCCI (Homogeneous Charge Compression Ignition) Gasoline Engine Supercharged by Exhaust Blow Down Pressure. SAE Paper 2007-01-1873. 